\title{
ROLE OF DESTINATION MANAGEMENT AND MARKETING ORGANIZATIONS IN REGIONAL DEVELOPMENT
}

\author{
S. Timareva ${ }^{1 *}$, E. Arabska ${ }^{2}$, I. Shopova ${ }^{1}$ \\ ${ }^{1}$ Department of Regional development and tourism, University of Agribusiness and Rural \\ Development, Plovdiv, Bulgaria \\ ${ }^{2}$ Department of Agribusiness and General Science, University of Agribusiness and Rural \\ Development, Plovdiv, Bulgaria
}

\begin{abstract}
In recent years Destination Management and Marketing Organization (DMMOs) became a mainstream factor in identifying successful development of a destination and its perspectives for better position in highly competitive tourism markets. They are not only representing a specific destination but are also striving to community development that bring long-term benefits such as attracting more visitors, increasing the economic gains, facilitating future marketing and product development decisions, and generally contributing to regional development through improving community relations and partnership. The paper discusses the roles of the DMMOs in destination management and their structure in relation to regional development. The destination mix elements of Plovdiv and the region and networking realities are presented. Plovdiv is rapidly establishing itself as a tourism destination in Europe and is working hard to strengthen the links between all tourism stakeholders directly or indirectly connected to the destination management. The city's destination management is analysed based on certain activities of organizations involved in tourism development and some recommendations are given.
\end{abstract}

Key words: sustainable development, tourism, destination mix, rural, networking.

\section{INTRODUCTION}

The processes of globalization and urbanization in modern world have led to a number of challenges before states and international community connected to sustainable regional development and policies targeted to overcoming economic disparities, strengthening social inclusion, reducing poverty and assuring safe and quality food and healthy living environment. Regional development is influenced by various factors as: market orientation, standard wage rate, competitiveness, structure of qualification, development of regional employment structure, soft factors considering life quality (1). Most often regional development is discussed in the context of rural areas as the ones in the worst status regarding economic and social development, which is the object of

\footnotetext{
* Correspondence to: Stefka Timareva, Faculty of Economics and Management, Department of Regional development and tourism, University of Agribusiness and Rural Development, Plovdiv, Bulgaria, 78 Dunav Blvd., Plovdiv 4003, tel. +359 889 862654, fax +35932960 406, stefkatim@abv.bg
}

different strategic documents for future development in the years till 2020 on European and national level. Development of rural regions in the new program period 2014-2020 in Bulgaria will be marked by special support measures in the field of environmental protection, good agricultural practice and raise of attractiveness not only through encouragement of agricultural activities, forestry and protected areas but also through diversification of activities, incl. tourism development (2).

Tourism is a key sector of the EU economy. There are many official reports and surveys that support with numbers this statement and highlight the importance of analyses in trends influencing tourism development (3-5). Tourism is scrutinized as an inducer of positive changes for regional development in three different directions: as a conservation tool, as a social catalyst and as an income and employment opportunity (6).

Responsible tourism is determined as "the most economically, socially and environmentally efficient approach, a real opportunity for 
exploiting and promoting local products and services" stimulating interest in nature, traditions and communities, respect towards environment minimizing the negative and maximizing the positive impacts through harmonization between nature and traditional living environment, unique customs and lifestyle of communities as part of the tourist attractions (7). Identification of tourism potentials is closely related to the achievement of destination competitiveness on tourism market and future actions should be related to promotion of tourist products within the regions, respect of principles for sustainable development, protection of natural environment, urgency of defined policy, priorities and activities (8).

There is an increasing interest in the destination management, as more and more places are striving to put their name on the map of the world tourism. On the other hand, tourists also become more demanding and looking for new and unique ways to experience the destination. Different factors influence their choice: price and quality correlation; green and sustainable footprint; collaborative consumption and authentic services, etc. The demand change directly affects the marketing mix of the destination and service economy has been slowly transforming to experience economy.

Current study examines the role of tourism in regional development through establishment of destination and marketing organizations considering their functioning, capacities and deliverables. Special focus is put on the region of Plovdiv as a tourist destination having been in rise for several years because of the special support measures undertaken by the local authorities and effectiveness of networking between stakeholders which is in the essence of destination management and marketing.

\section{ROLES OF DESTINATION MANAGEMENT AND MARKETING ORGANIZATIONS}

Destination marketing organizations are defined by the Destination Marketing Association International (9) as organizations "charged with representing a specific destination and helping the long-term development of communities through a travel and tourism strategy" regarding the organizations as valuable for visitors, business travelers or planners especially because of the information provided and saved time and energy and they are viewed as " $a$ one-stop shop for local tourism interests". The most important point is the networking opportunities and realities bearing great benefits for all involved.

Destination management is the coordination and integration of all of the elements of the destination mix in a particular geographic area based upon a defined tourism strategy and plan. The destination mix elements are the attractions and events, facilities (hotels, restaurants, etc.), transportation, infrastructure, and hospitality resources (10). In addition, destination management encompasses the image-making, branding, and marketing and communications of all that the place has to offer to tourists. Destination management organizations (DMOs) have the overall responsibility for the coordination and integration of the destination mix elements, and for destination marketing. They are scattered throughout the world and spanning many different organizational sizes and types. Many DMOs are government departments, while others are quasi-governmental. DMO structures vary according to local practices and governmental systems.

Destination Consultancy Group (DCG) (11), a US-based tourism consulting company, identifies the roles of the DMO in destination management as leadership and coordination; research and planning; product development; marketing and promotion; partnerships and team-building; and community relations. The main role of a DMO consists of fulfilling marketing, promotional and sales tasks, as well as coordinating long-term destination planning and management since the consumer perceives and buys a destination as one integrated product (12).

The management and marketing roles of DMMOs are identified in rural tourism destinations as follows: network management organisations, organiser, community brand builder, funding agent, catalyst, advocate, tourism product developer, convener and facilitator, information provider, partner and team builder. (13) Their roles are in the spheres as: collaboration with tourism destination stakeholders in achieving mutual benefits in management of resources, marketing of tourism products, positioning, host community well-being, brand building and tourism loyalty to rural destinations (13). Roles of destination and marketing organizations could be divided in two groups (Table 1) underlying the framework of such organizations and the need of good management. 
The fact that tourism is connected to other sectors development (infrastructure, communications, transport, agriculture, food industry, etc.) should be carefully considered. Different synergy effects from the interaction of tourism and other local industries are categorized (14): product synergy - local food industries offer tourist products based on existing buildings, competence, etc.; market synergy - marketing effects of tourists visiting and tasting products, and joint advertising of the place.

Table 1. Roles of destination and marketing organizations

\begin{tabular}{l}
\hline Destination management roles \\
Human resource development \\
Finance and budgeting management \\
Safety, security and crisis
\end{tabular}

Politics (government, non-governmental organizations, community relations and industrial relationships), policy and destination strategy Monitoring service quality, standards and destination performance management

\section{FUNDAMENTALS OF DMMOS ESTABLISHMENT AND FUNCTIONING IN BULGARIA}

Developed in accordance to the Strategy of smart, sustainable and inclusive growth Europe 2020, National development program Bulgaria 2020 (15) puts priorities in the achievement of sustainable and integrated regional development on the basis of local potentials and sustainable management of natural resources in which one of the sectors in the special focus is tourism and tourism marketing, diversification and networking. National strategy for sustainable tourism development 2014-2030 (16) is targeted to raising competitiveness of the country as a tourist destination and making contribution to sustainable tourism development. The management of marketing tourism regions embraces activities in three directions: creation of regional tourist products; regional marketing and advertisement; coordination and management of tourism on regional level; creation of tourist zones and organizations for their management - improving marketing, effective use of resources and coordinated activities (2).

In some previous analyses of national strategic documents on different levels concerning tourism development in the country (17) main conclusions are focused on the need of finding the right ways of implementation of strategic goals. Bearing in mind the opportunities and roles of DMMOs, the opportunities of application of DMMOs according to national conditions are explored through making a SWOT-analysis (18). The SWOT-analysis

\begin{abstract}
Destination marketing roles
Destination marketing communication

Destination positioning and branding

Management of tourism assets, attractions

management and sustainability

Service quality, tourist experience and customer's

relationship management
\end{abstract}

Tourism product development and management 
and rural development and provision of sustainability.

\section{DESTINATION MIX OF THE CITY OF PLOVDIV AND TRAKIA REGION}

Plovdiv is developing cultural torusim destination and it is an example for good ellaboration in regional level. The city recently won a European Capital of Culture event for 2019 and it is a result of several years of concerted efforts to promote the city as a tourism destination. According to statistics, announced by the official tourism portal of Bulgaria (19), in May 2014 the flow of foreign tourists in Plovdiv has led to an increase in tourism revenues by almost $50 \%$ compared to the previous month and by $55 \%$ compared to the same period last year. According to NSI data (20), the number of nights spent increased by $20.11 \%$. Bulgarian tourists increased by $7 \%$ and foreign tourists - by $43 \%$. According to the municipal enterprise "Tourism" (21), tourism tax income rose by $25 \%$ compared to 2013 . There is also $11 \%$ increase in visits to tourist sites in the period January-June 2014 compared to the same period in 2013. Tourist information centers for the period from January to June 2014 have been visited by 30\% more foreigners and 56\% - Bulgarians. Despite the obvious opportunities to develop cultural tourism and other forms of alternative tourism in cooperation with neighbouring municipalities, only last two years Plovdiv reported progress. Part of this successful development is due to local initiatives by the municipality and the citizens. Figure 1 summarised the relations in Plovdiv destination mix development which are very important for planning and management.

Plovdiv has also an innovative Strategy and Action Plan for sustainable development of tourism within the period $2014-2020$ (22). A special consortium for tourism strategy of Plovdiv was designed to assess available resources for tourism development and their conversion into tourism assets. The tourism industry is a complex industry that depends not only directly on the level and capacity of the main suppliers of travel services (transport, accommodation and food), but also from many other common industries. In Plovdiv they are mainly related to cultural and creative industries, education, light industry and communications. Among the main resources for tourism development are physical and geographical characteristics, cultural heritage, human resources, infrastructure, products and services, as well as economics and politics at the regional and municipal level. These resources, combined with market needs, available capacity and quality requirements, become assets for tourism offering, whose base is created competitive tourism products (22).

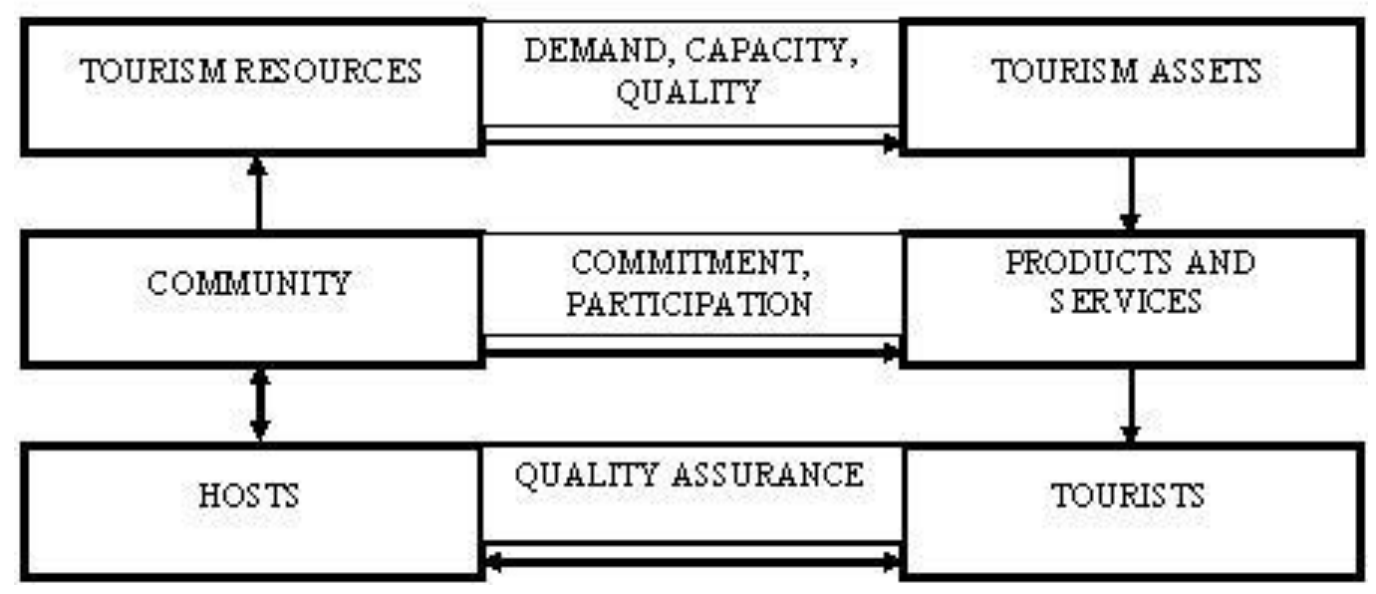

Figure 1. Destination mix of Plovdiv

Priority types of tourism, which Plovdiv has developed many assets, are cultural, wine and gourmet, business, congress and event / festival, sports and weekend / urban / shopping tourism. Cultural tourism is essential for Plovdiv with the most developed resource base and also best used assets. It represents $60 \%$ of foreign tourists flow to the city, and about $45 \%$ Bulgarian tourists' flow, regardless of the main reasons for visiting the city (22). Besides the presence of the famous archaeological sites of world importance, the city organized many cultural events that add value to the tourism product. To be imposed, however, cultural tourism requires active advertising and visibility from the tourists. In the city operates several enterprises and organization that could play the role of DMO and their common activities will bring advantages to tourism performance. These are Tourism Council, 
Municipality Enterprises "Tourism" and "Old Town", Consultative Council of Tourism, Tourism Directorate of Ministry of Tourism, Tourist Information centers in Plovdiv, Thrace region tourism (according to the Tourism Zoning of Bulgaria). There are also many public and private partners involved in sustainable development of Plovdiv as tourism destination like Plovdiv 2019 - resources and factors for tourism development, Free Plovdiv Tour, Regional Chamber of Crafts etc. The annual events are a major resource for the development of tourism in Plovdiv. They promote the city as a center of culture, business and congress tourism, as well as sports and event tourism.

The Tourism Council of Plovdiv (23) is a nonprofit organization, which is also actively involved in the cultural calendar of the city as an organizer of cultural events and activities. The Council coordinates the interests and the activities, as well as activates the enterprise of different authorities, organizations and companies, related to development of tourism in the area. It contributes to develop tourism in a particular region, encourages the private enterprise, coordinates and regulates the relations in creating and realizing the tourist product. The Council represents its members in front of the regional tourism organizations, The Bulgarian National Board of Tourism and the national authorities. Among its main activities are coordination and implementation of different programs; actively participation in local tourism related projects and discussions; organization of joint initiatives, cooperation and coordination between the private and the public tourism branch in the region; processing statistical data for the state of tourism development in the municipal region. The Council well cooperates with local tourist information centers and supports their activities. It also ensures the one-way and coherent aspect of the intensions and the activities of the commercial subjects in tourism field in establishing and realizing the marketing activity and development of one complex tourist product.

For the protection, maintenance and promotion of cultural and archeological heritage of the city, the Ancient Plovdiv Municipal Institute was established with Municipal Council decision in coordination with the Minister for Culture as a municipal cultural institute. It implements the municipal policy for protection and development of cultural heritage in line with the principles of national cultural policy and local traditions. Its mission is about making conservation activities and protection of movable and immovable cultural values available for managing "Old Town". The Institute carries municipal policy for development and protection of cultural heritage in accordance with the principles of national policy and local traditions. It manages and controls all activities of restoration, conservation, rehabilitation, landscaping, lighting and management of the territory of the architectural reserve "Old Town". Cultural and information activities in the reserve are carried through this Institute and provide advanced capabilities for development of cultural tourism, fundraising, constant monitoring, documenting, archiving. Events attract tourists and often support destination marketing as good option to spend time while the tourist is on vacation. Summer Music Festival at the Ancient Theater, Plovdiv (Verdi operas), rock and jazz concerts attract many visitors. Due to the good acoustics and specific architecture the Ancient Theater in the Old Town is used for concerts and other public events. One Design Week, One Architectural Week, One Dance Week were held in Plovdiv in 2014, which is very important reason to create specialized products connecting with them as well as with already established major cultural events and festivals in the city. Plovdiv is a destination with high competitive tourist industry. Based on the resources that the city and its surroundings have and using DMOs can be developed various forms of tourism. They will help to promote the conversion of the city into an attractive European destination, generating basic and additional incomes from tourism.

\section{GOOD PRACTICES IN DESTINATION MANAGEMENT AND MARKETING IN PLOVDIV AND TRAKIA REGION}

Official voted status of the city for European Capital of Culture is recognition of Plovdiv and a chance for Bulgaria to come to the fore of the cultural map of Europe and to become more visible and recognizable. It is a result of the work of a number of supporters and contributors, especially from private and nongovernmental sector uniting and attaining the final goal. Some good practices are presented below which is an example in destination marketing and management.

Festival "Young Wine Parade " is a trademark registered by the Tourism Council of Plovdiv, for organizing and conducting of young Bulgarian wines degustation within the last Friday, Saturday and Sunday of November in different houses and open spaces in the Old Town. The event aims to promote the uniqueness of Plovdiv, the good quality of the young Bulgarian wine and to attract more 
tourists and visitors to the city and the country. In the cozy atmosphere of the Revival houses of the Old Town, the festival guests have the opportunity to taste the young wine, produced in different regions of the country. The event, which began as a two days celebration with 16 participants in 2009 in 6 Revival houses, very quickly gained popularity. Only three years later, in 2012, already 25 wine cellars from all over the country introduced their production in 8 houses and 2 restaurants in the Old town. In just 4 consecutive years "The Young Wine Parade" grows to a seven days festival in which the wine producers present their production in a world's unique format. For five years the event has grown to seven days festival where more than 10000 visitors have been tasting young Bulgarian wine last year according to official data, presented by the Tourism Council (23).

The policy of the municipality of Plovdiv in tourism is conducted by the Municipal enterprise for tourism which promotes the city as an attractive tourist destination in the country and abroad. Among the activities organized are tourist product-related advertising campaigns, conferences, seminars and other events. The contacts with tourist information centers in Bulgaria and tourismrelated schools in the city as well as industry representatives, regional and national tourist organizations provide opportunities for the application of new approaches in destination management and marketing, The enterprise has two information centers in its structure situated in Plovdiv and providing information about the city and the region to Bulgarian and foreign tourists and Plovdiv citizens.

2010 the Trakia Tourism Region was established as a public benefit non-profit organisation and after approving of the Bulgarian tourism zoning it became the main brand presenter of the region. The main objectives of the Trakia Tourism Region, as defined in the Articles of Association, are namely: to partner the Ministry of Tourism or its successor, as the body which determines state tourism policy and legal regulation for the development of the tourism industry in conducting regionally differentiated policy; to unite local and entrepreneurial initiatives within the Trakia Tourism Region to tackle fragmentation problems and "localism" of product development, marketing and advertising, and the limited resources of individual companies and local communities; to create a trademark (brand) for the Trakia Tourism Region; to conduct effective advertising of the Trakia Tourism Region within the country and abroad, in line with its specificity and image, resources and opportunities for various types of tourism through a range of advertising channels (international and national tourist markets and exhibitions, publications in the foreign press and advertising in mass media, etc. ); to market the Trakia Tourism Region; to represent and protect the interests of its members; to assist in attracting investors to the Trakia Tourism Region to work to unite the interests and actions of the executive and local government and non-governmental organisations on the territory of the Trakia Tourism Region; to work with national and regional media to attain its goals (24).

Municipal Foundation "Plovdiv 2019" was established in 2011 by Plovdiv's City Council and its main objectives are to develop projects and to prepare Plovdiv's bid documents European Capital of Culture in 2019. The foundation works with a wide range of partners amongst which are the local administrative bodies along with European, national and local institutions; educational establishments; youth formations; professional associations; cultural operators; business partners; public organizations; local, regional and national media; citizens (25).

Free Plovdiv Tour, one of the projects of the 365 Association, officially registered in 2010 and it is fast developing organization in the sphere of guide services. Now the team numbers 60 people. More than 55000 people from 130+ countries have been welcomed to Bulgaria. TripAdvisor rated the walking tours as number one attractions. Among the main goals of the organization are to turn Bulgaria into a popular destination for tourism and culture; to improve the quality of the tourist services; to engage young people into active civil participation; and to create conditions to encourage multicultural exchange. Besides that the tour has widespread approvals by tourists, it impresses for its consistency to enhance the quality of their work. Joint initiatives, sharing knowledge and skills with Tourist Information Center and the Association of guides in Bulgaria would only benefit to increase the quality of the final product (26).

\section{CONCLUSIONS}

Plovdiv and its vicinities will definitely be among the top Bulgarian tourist destination for next years, not only because the European capital of culture events but also because the rich cultural and historical heritage in the region, especially from ancient ages, and the significant efforts put into development of 
tourism activities and products. Although positive growth and trends, there is still a need of improving destination performance through better management and marketing as a number of state, municipal, private and nongovernmental organizations do coordinating activities of each other and uniting for achievement of common goals. Joint project work is necessary more than ever for preservation of the resources of destination, making it suitable for tourism through infrastructure and capacity building, new marketing tools and management instruments for improvement of destination performance and assurance of sustainability.

\section{REFERENCES}

1. Heidelbach, O.,Agriculture in a transition economy - a regional analysis of the mountainous region of County Alba, Romania. M.Sc. Thesis. 2002 Available from: http://www.proiectapuseni.org/dokumente/fachberichte/thesis_ heidelbach.pdf. [Accessed: 01/2015].

2. Terziev V., Arabska E., Grigorova Z., Management of agriculture and tourism in mountain region for sustainable development. Exclusive economic reforms in conditions of risk and uncertainty. Conference proceedings of International scientific and applied conference 31 January 2015, UFA - Aeterna, 3-14, 2015.

3. UNWTO, Tourism Highlights, 2014.

4. UNWTO, World Tourism Barometer, January, 2015.

5. WTTC, Travel\& Tourism economic impact, European Union, 2014.

6. Nepal, S.K., Tourism as a key to sustainable mountain development: the Nepalese Himalayas in retrospect, Unasylva 208, 53: 38-46, 2002.

7. Petrovici A., Public Relations in Tourism. A Research on The perception of the Romanian public upon responsible tourism. Procedia - Social and Behavioral Sciences 163, 67-72, 2014.

8. Nestoroska I., Identifying tourism potentials in Republic of Macedonia through regional approach. Procedia Social and Behavioral Sciences 44: 95-103, 2012.

9. Destination Marketing Association International:

http://www.destinationmarketing.org/faq.

10.Morrison A., Destination Management and Destination Marketing: The Platform for
Excellence in Tourism Destination, 2013. Available at ResearchGate..

11.Destination Consultancy Group (DCG) web-site http://dcgconsulting.com/.

12.Klimek, K., Destination management organisations and their shift to sustainable tourism development, European Journal of Tourism, Hospitality and Recreation, Vol. 4, Issue 2, 27-47, 2013.

13.Adeyinka-Ojo, S. F., Khoo-Lattimore, C., and Nair, V., A framework for rural tourism destination management and marketing organisations. Procedia - Social and Behavioral Sciences 144, 151-163, 2014.

14.Holmefjord K., Linkingproducts, industries and place - synergy effects from the interaction of tourism and other local industries in Lofoten and Hardanger, SNF Projec No 6490. Working paper 85/00, 2000.

15. National development program Bulgaria 2020. Available at: http://strategy.bg.

16. National strategy for sustainable tourism development 2014-2030. Available at: http://strategy.bg.

17.Shopova I., E. Arabska, Sustainable tourism development in rural areas, 4th International Conference of Economic Sciences; Quality of Life, Sustainability and Locality; 9-10 May 2013 - Kaposvár University - Kaposvár - Hungary, 535-546, 2013.

18.Terziev V., Arabska E., Opportunities of establishment of destination management and marketing organizations in Bulgaria. International conference Enterprise and the Competitive Environment, March 5 - 6, 2015, Mendel University in Brno.

19. Official tourism portal of Bulgaria: http://bulgariatravel.org/.

20.National Statistical Institute: http://www.nsi.bg/.

21.Municipality Enterprises "Tourism": http://www.plovdiv.bg/.../tourism/.

22.Plovdiv Tourism Strategy: http://www.plovdiv.bg/.

23.Tourism Council: http://www.tourismplovdiv.org/.

24.Trakia Tourism Region / Thrace region tourism/: http://trakiatour.com/en/.

25.Plovdiv 2019 -resources and factors for tourism development: http://plovdiv2019.eu/.

26.Free Plovdiv Tour: http://www.freeplovdivtour.com/. 